\title{
Solar action plans in European cities
}

\author{
A. Mueller ${ }^{1}$, S. Linder ${ }^{1}$, E. Caamaño-Martin ${ }^{2}$, E. Higueras ${ }^{2}$, \\ F. J. Neila ${ }^{2}$, I. Useros ${ }^{2}$, X. Marrero ${ }^{3}$, A. Alonso ${ }^{3}$, A. Saade ${ }^{4}$, \\ M. Jedliczka ${ }^{4}$, M. de l'Epine ${ }^{4}$, Y. Françoise ${ }^{5}$, J. Bigorgne ${ }^{6}$, \\ E. Kjellsson ${ }^{7}$, A. Cornander ${ }^{8}$, J. Fernandes ${ }^{9}$, R. Arndt ${ }^{10}$, \\ S. Pintarits ${ }^{10}$ \& E. Wildbrett ${ }^{11}$ \\ ${ }^{1}$ Ecofys GmbH, Germany \\ ${ }^{2}$ Politechnical University of Madrid, Spain \\ ${ }^{3}$ City of Vitoria-Gasteiz, Spain \\ ${ }^{4}$ HESPUL, France \\ ${ }^{5}$ City of Paris, France \\ ${ }^{6}$ Atelier Parisien d'Urbanisme APUR, France \\ ${ }^{7}$ University of Lund, Sweden \\ ${ }^{8}$ Skane Energy Agency, Sweden \\ ${ }^{9}$ Lisboa Enova, Portugal \\ ${ }^{10}$ City of Munich, Germany \\ ${ }^{11}$ Local Energy Agency of Grand Lyon, France
}

\begin{abstract}
POLIS (Identification and mobilization of solar potentials via local strategies) is funded under the Intelligent Energy Europe (IEE) Programme aiming at the implementation of strategic town planning and local policy measures to activate the solar ability of urban structures in European cities (www.polis-solar.eu). The aim is to present and evaluate current developments and bring together key stakeholders of this process to improve planning/legislation practice towards a solar development. With respect to the urban structures and composition of buildings the importance of solar energy is evident, since the shape of constructive structures and relevant surfaces are the basis for application of solar systems and for receiving passive solar gains. To ensure the solar use certain requirements need to be included in development planning and building legislation. In addition, existing buildings need to be qualified for the application of
\end{abstract}


solar systems. POLIS project brings together local authorities with different experiences and varying states of urban development from France, Germany, Portugal, Spain and Sweden, to share their knowledge on solar town planning and encourage further activities within the scope of an expert network for cities.

Keywords: solar urban planning, solar development, passive solar gains, solar potential, solar energy supply, solar mobilization, improvement of planning and legislation practice.

\section{Introduction}

Each of the 6 participating cities of POLIS project in particular (Lyon and Paris in France, Munich in Germany, Lisbon in Portugal, Malmö in Sweden and Vitoria-Gasteiz in Spain) have committed to long-term strategies to integrate solar energy at urban level that are consistent with existing $\mathrm{CO}_{2}$ mitigation targets (related to national/regional requirements or voluntary commitments, for example, the Covenant of Mayors is signed by all POLIS participating cities) in solar Action Plans embedded in local planning. In this paper an overview of current conditions in POLIS cities and their solar action plan is described. Several short-term measures have been identified, including specific priorities to be implemented as "Pilot Actions" within POLIS.

The project target is the implementation of strategic town planning and local policy measures to activate the solar ability of urban structures in European cities. Only urban approaches can enhance the broad integration of small-scale solar energy applications in the built environment. Lately diverse new technologies and legislative opportunities have been developed concerning potential analysis and its mobilization. The aim is to present and evaluate current developments and bring together key stakeholders of this process to improve planning and legislation practice towards a solar development. With respect to the composition of buildings and urban structures the importance of solar energy is evident; for shape of constructive structures and relevant surfaces are the basis for application of solar systems and also for receiving passive solar gains. Therefore, solar energy, more than other RES, is connected to the form, function and arrangement of buildings. Ensure that new structures have the ability to fit a solar energy supply; certain requirements need to be included in development planning and building legislation. Here several instruments are available to prescribe solar targets like municipal agreements or private law commitments. Also, in some countries the national building code already provides the possibility of solar relevant specifications. The project focuses on local options regarding municipal commitments to elevated requirements.

\section{Lyon}

\subsection{Background}

In 2005, the Greater Lyon had 543,230 residential buildings: $81 \%$ of these were collective housing, the rest is individual housing. Approximately $25 \%$ of roofs 
were on industrial or tertiary buildings in industrial zones. There is a strong dynamic on the territory because about 40,000 collective housing and 8,616 houses were built between 1999 and 2005. Electricity generation is extremely centralised in Lyon, with a well established distribution grid in place. Five thermal energy distribution networks exist in some areas for district heating, with localised heat plants. Renewable energies correspond to $3.8 \%$ out of Greater Lyon total energy consumption. Currently, the energy supplied by solar energy (thermal and photovoltaic) is not significant (approximately $0.01 \%$ out of the total energy consumption).

\subsection{Action plans}

In December 2007, Grand Lyon councillors unanimously voted a Climate Action Plan. The specific target of $20 \%$ share of renewable energies by 2020 implies very concrete goals for solar technologies equivalent to increases of $65 \%$ per year for PV technology and 50\% per year for solar thermal. The development of renewable energies and notably solar, therefore does represent a strong part in the Energy Action Plan. The Lyon solar Action Plan comprises the following four major categories:

- Disseminating knowledge about the solar potential of buildings: An interactive website with estimated solar potential for all buildings of Grand Lyon and detailed solar potential for inhabitants of Sainte Blandine district should be developed.

- Putting investors in connection with solar: Citizen jointly owned PV systems with correspondnig communication instruments should be developed. In addition to this a Guideline for businesses to facilitate investments in solar facilities, where different alternatives will be considered (investment in companies' own buildings, roof rental, co-financing of facilities located in other buildings, cooperative investments, etc.) will be worked out. Accompanying to this existing financial mechanisms and tools to local government will be promoted. Research will be done about the advantages of purchasing groups e.g. to obtain lower investment prices in solar equipment.

- Optimising solar energy in urban planning: Solar aspects should be integrated into planning documents of new development areas. On the base of a pilot development area where scenario will calculted and solar requirements will be integrated in the local urban planning documents and studies/manuals these solar aspects will be defined. Furthermore a new Housing Guidelines to incorporate mandatory solar targets will be developed.

- Involving communities in the development of solar energy: Lyon will integrate compulsory objectives for renewable energies for instruction of building permits. Furthermore a Solar Plan for integrating PV and solar thermal installations into buildings owned by Grand Lyon will be formulated. The city will particpate in the the current public and private thinking concerning the creation of a real integrated industrial network, from Silicon production to the maintenance of installations. In addtion to this a study of the regulation and tax tools available to the communities will be done in order to encourage private investment. 


\section{Paris}

\subsection{Background}

The City of Paris has around 100,000 buildings with a total surface of 120 million sqm (with a share of round $58 \%$ residential and $41 \%$ tertiary). Two major features of Paris city are that there is almost no industrial sector and a large steam network (first network in Europe). Current estimate of the share of renewable energy consumption in the Paris area is $6.1 \%$. According to the current survey to establish the potential of RES for the City of Paris, solar thermal represents $0.7 \%$ of the RES production in Paris, and PV represents $0.1 \%$. Currently, city of Paris finances a special survey to establish the installed solar capacity and the global potential of RES for the City by 2020. According to this study, solar thermal installations represent $51 \%$ of all RES equipment installed in Paris and $18 \%$ is PV facilities.

\subsection{Action plans}

In 2007 the City of Paris voted the Paris Climate Protection Plan to combat greenhouse gas emissions generated by various activities in Paris. This strong commitment is based on a "factor 4" approach and aims to result in $75 \%$ less greenhouse gas emissions from its own activities and those of Parisian territory by 2050 compared to 2004. Targets set for Paris in 2020 are more ambitious than EU objectives, namely $25 \%$ less greenhouse gas emissions, 25\% less energy consumption and $25 \%$ of Paris' energy consumption to come from renewable energy sources. Thus the development of renewable energy is a major strand of the Climate Plan of Paris to reduce the carbon footprint of the territory. The Paris solar Action Plan comprises three main stages, diagnosis, mobilization of solar potential and communication, according to a dynamic approach where revisions and annual updates are expected. Within Paris solar Action Plan the following targets have been defined:

- Detailed assessment of the solar thermal and PV potential of the whole city building stock by 2012, combining the results of ongoing studies about renewable energies potential and feasibility studies regarding solar energy on municipal public and private properties in an interactive map for professionals and citizens. A modelling tool will be developed to identify the technical solar potental (PV + thermal) of the city's complete building stock. In addtion Paris wants to develop a monitoring tool to improve knowledge about the existing solar equipments and follow the installation of new ones on territory will be developed. Feasibilty studies will done to to assess the solar possibility for example Possiblities of installing solar thermal systems for the existing swimming pools.

- Mobilization of solar potential: The target is the installation of 200,000 sqm of solar panels in Paris by 2014 to reduce the Parisian carbon footprint. Paris will asses existing also historical buildings in order to incorporate solar PV facilities while preserving their architectural characteristics. PV potential on 
best suited roofs according to the results of previous analysis will be mobilised. Public-private joint venture dedicated to the renewable energies development will be created, aiming to facilitate the understanding of solar facilities and developing "energy services" activities related to energy efficiency. Next to this Paris wants to establich a citizens investment fund for private persons willing to generate PV electricity that would buy shares in a collective facility or invest in a fund specifically dedicated to PV.

- Definition of realistic targets for 2020 for solar technologies (solar thermal and photovoltaic) in the whole city area by 2012, based on the feasibility studies about renewables and specifically solar technologies and the assessment of solar potential of the city building stock.

- Set of requirements for solar energy is integrated in the local Urban Planning Plan by 2013, thus anticipating the opportunity opened by the new Environmental Law. Paris wants to identify possibilities of including solar requirements in urban planning documents. Setting of requirements in local plans will be developed, aiming to remove current barriers for the potential for solar developments in the city of Paris and identifying possibilities of including solar requirements in urban planning documents.

- Communication: Paris will raise awareness by solar campaigns to inform citizens' organisations about integration of solar technologies at urban level: building permits, guidelines, eligible solar equipment and installers, available aids, procedures. Beside of this Paris will organise development aid for professionals of the solar energy sector in Paris, integrated in the activities carried out by the Paris Development in order to share expertise with companies having implementation projects in Paris and/or holders of innovative projects.

\section{Munich}

\subsection{Background}

In general all buildings in Munich can be differentiated regarding age and kind of use in 62 urban types. Around 153,000 residential buildings exist in Munich with an amount of 776,800 units and thereof $50 \%$ in multiple family houses. In the years 2005-2009 around 7000 units per year were newly constructed. In 2008 the share of renewable energy of the produced energy was $3.75 \%$. Regarding installed capacity of solar technologies a total area of around 55,000 sqm of solar thermal collectors and $17,322 \mathrm{kWp}$ of PV modules have been installed in Munich. According to local conditions several potential studies have been carried out. The identified technical potential of building integrated photovoltaic is 1.69 TWh per year. This would be $29 \%$ of the total power demand in Munich. The identified technical-economic potential is around $9 \%$ of the total electric power demand in Munich. Partly new urban plans were solar optimized with "Solenop" (area with more than 500 dwellings). 


\subsection{Action plans}

The City of Munich is one of the pioneer German cities in relation to sustainability concepts of energy supply. Within Munich solar Action Plan the following long-term targets have been defined:

- Support and mobilization of a PV potential: The target is that 3.5\% of Munich's power demand will be addressed through the "Solar Initiative Munich (SIM)" by 2015. The share of PV should be increased to additional $3.5 \%$ and the share of solar thermal of the heat demand to $3 \%$ in 2030 . In all new areas $>100$ units the share of passive solar gains of the overall heating demand should reach $25 \%$.

Main areas of intervention identified are residential areas and areas of diverse use, urban renewal areas, specific quarters, existing and new commerce and industry areas, areas of infrastructure and new buildings in existing areas.

- Proactive public relations: There should be a pro-actively information supply through different media to public and expert audience about solar energy aspects and potentials. The competition "München_ganz schön solar - solar planning and building" can support this.

- Increase of expertise: Munich wants to improve internal knowledge and expertise in Munich municipality through knowledge transfer (individual and IT-based procedures). Part of this strategy is to establish an internal expert team consisting of relevant staff members of the various (main) departments of Munich municipality in order to improve internal cooperation in relation to solar urban planning

- Planning process: Munich will develop a POLIS Guideline for solar urban planning" to facilitate a criteria based assessment of planning documents and projects: development of indicators and criteria, guideline of activities in development areas (competition and promotional grants), catalogue of ecological criteria, urbanistic agreements and grant programmes. Furthermore energy aspects should be integrated in the Geographic Information Systems (GIS) to provide answers related to urban development and solar urban planning, including elegibility of areas to mobilize the existing solar potential. Futher research and the development of instruments will be done to support active solar energy through permission process.

- Implementation: The "POLIS Guideline for solar urban planning" will be implemented into a new development area. The experience made will be integrated into a revised POLIS guideline. Munich will develop strategies and measures of implementation in the building stock based on experiences with the POLIS pilot project and if necessary of other projects. The aassessment of introducing incentive program, development of technical requirements of (solar) energetic optimization within the urban redevelopment/refurbishment will be integrated in this strategy. The the (solar) energetic objectives and applications in urbanistic contracts will be adjusted.

- Municipal approval process: Munich will enforce the national renewable heat law. In addtion to this the ecologic criteria catalog of the City of Munich will 
be adjusted to the legal requirements (EEWärmeG and EEG).

- Subsidy schemes/basic conditions: The share of solar energy in existing buildings should be increased. A realistic target value of the yearly enhancement of supported solar thermal will be evaluated and fixed. Furthermore the framework for the application of solar energy will be improved.

\section{Lisbon}

\subsection{Background}

According to the Lisbon's Local Plan for Housing, there are presently 53,387 buildings in Lisbon, 41,295 of which are purely residential. The average age of buildings is 53 years, which reflects a lower rate of new constructions over the years and an almost inexistent rate of refurbishment works. Apart from the number of total or partially abandoned buildings there are 4,568 buildings that need to be seriously refurbished. For solar thermal systems, the total installed capacity has still not been evaluated. Nevertheless, from the energy certification system it is possible to identify, within the pool of certified dwellings, how many have already installed solar thermal collectors and how many buildings still in construction are expected to install solar thermal systems. Lisbon accounted for a total installed PV capacity of $200 \mathrm{kWp}$ in May 2009. At the level of municipal regulations for building and urbanization the Lisbon Municipality has already narrowed more demanding requirements in place that are in compliance with current legislation in force (particularly with regard to the mandatory installation of solar thermal panels defined in Thermal Performance Building Regulation), promoting a more efficient adoption of renewables. In addition, at the national level it is established that any construction or reconstruction work must consider the existence of natural light improving the building orientation and design towards receiving direct solar radiation.

\subsection{Action plans}

The City of Lisbon approved in December 2008 the Energy-Environment Strategy for Lisbon, setting targets for energy consumption reduction at the Municipality and the complete city level of $8.9 \%$ and $9.4 \%$ respectively, by the year 2013 (based on 2002 consumption levels). Focusing on this same baseline, the City of Lisbon also undertook the Covenant of Mayors compromise to reduce $\mathrm{CO}_{2}$ emissions over $20 \%$ by 2020 . The current local energy policies already focus on the dimension of energy efficiency and renewable energies, especially at the micro-production level. At the level of municipal regulations for building and urbanization the Lisbon Municipality has already narrowed more demanding requirements that, in compliance with current legislation in force, promote a more efficient adoption of renewables. In the City of Lisbon, the current focus of public policies now aims at urban requalification and building refurbishment, bringing together the best practices and adoption of new technologies with the 
built heritage. For the city of Lisbon, an initial assessment has been made to extrapolate Portugues National Action Plan for Energy Efficiency targets (PNAEE) for micro-production and solar thermal systems on residential buildings, giving a total amount of $2 \mathrm{MWp}$ and 13,600 sqm for PV and solar thermal technologies, respectively. The definition of more specific targets for the adoption of solar technologies has to take into account the actual urban potential based on existing conditions, which is unknown yet. Therefore, a detailed study to quantify the urban solar potential of the city is considered of highest priority within the Action Plan. The adoption of public policies for the integration of solar urban planning guidance will derive also from the results of the assessment carried out at the local level. Main areas of intervention identified to address in promoting the uptake of solar urban planning are:

- Evaluation of the solar energy potential in the City of Lisbon and provision of information about the solar potential of Lisbon to the public. Lisbon will evalute the solar potential at parish level, focusing on the local framework regarding housing refurbishment and providing the results obtained to the general public. Furthermore the potential to integrate solar technologies in the Neighbourhood Boavista Urban Plan will be evaluated, identifying opportunities for redefining the urban design in order to maximize the plan's potential for adopting solar technologies.

- Setting targets for the adoption of solar technologies based on the potential identified at the level of the building stock. Lisbon will define realistic targets for solar technologies adoption (thermal and photovoltaic) in the medium and short term for the city of Lisbon and for Lisbon Municipality.

- Consideration of guidelines for the development of practical solar urban planning at the review of the Municipal Plan and the Regulation Municipal Urbanization and Construction of Lisbon.

- Contextualizing the policy framework for the adoption of solar technologies in the municipal strategy for the upgrading and rehabilitating of the city's building stock.

- Identification of urban plans for the application of the guidelines, with the consequent revision of urban design in order to maximize the adoption of solar technologies.

- Identification of the solar potential of the Lisbon Municipality's built heritage at the level of service buildings and buildings of municipal housing supplied with medium voltage.

- Promote the training of professionals in the fields of urban planning, engineering and architecture on the concepts of passive and active solar technologies. Training workshops for professionals (planners, engineers and architects) will be organised. 


\section{Malmö}

\subsection{Background}

The City of Malmö has developed from a garrison town in the late Middle Ages, into a shipping and transportation town, into an industrial city and today into an expansive big city with higher education. The City of Malmö is facing large investments in regeneration of the buildings from the post-war period. The energy types adding up to final energy use in Malmö within the period 19902006 show a quite stable or slightly increasing trend, except for fuel oils which were formerly a common source of heating but which have diminished rapidly in use $(80 \%)$. The consumption of electricity, petrol and district heating energy has each increased by $4-6 \%$ during the period. On the national level in Sweden, investment subsidies and grants are available, both for solar thermal and solar photovoltaic systems. The installed capacity of solar thermal is $2.5 \mathrm{MW}$. For installed capacity of PV is around $450 \mathrm{kWp}$ for the City of Malmö and in addition there are also a few private installations with capacity below $50 \mathrm{kWp}$. Contribution of solar energies to the local energy mix is so small that it is not measurable. At present, within the municipal Solar Energy initiatives in Malmö approximately $0.7 \%$ of the heat and $0.3 \%$ of the electricity used in the buildings within the Department of Internal Services comes from solar energy.

\subsection{Action plans}

In June 2006, the Swedish Parliament set the target that specific energy use in residential buildings and commercial premises should be reduced by one fifth by 2020 , further reducing to half of present day levels by 2050 . In addition, by 2020 , the dependence of the built environment on fossil fuels for energy supplies should be broken. Main areas of intervention identified to promote the uptake of solar urban planning are new and existing areas in order to have an important impact on the number of installed solar energy plants in Malmö. Solar energy requirements need to be introduced early in the planning processes of these areas. Relevant stakeholders of concern for the implementation of solar energy in connection with urban approaches are construction companies, municipal departments (including architects, planners and municipal building department), politicians and small as well as large scale private property owners. Within Malmö solar Action Plan the following targets have been set :

- Identification of measurable targets for active solar systems (PV and solar thermal) for the whole city area in 2012 for new and existing buildings. The potential of other areas of the city of Malmö will be assed. A methodology to identify the realistic solar potential of urban areas will be developed and applied to the Sege Park area.

- Introduction of solar energy requirements in the urban planning process in 2012 by using the new Environmental Program, Energy Strategy and Environmental Building Program South. Malmö will start to integrate solar energy requirements $n$ the area Sege Park. Guidelines will be developed to 
support solar energy planning that will be integrated into the new Energy Strategy and connected to the Environmental program.

- Exploitation and purchase agreements are developed with respect to solar energy requirements and are used in special areas from 2011. Malmö will integrate solar energy requirements in exploitation and purchase agreements for developers building on city-owned land

- Dissemination activities: Energy Agency will organise trainings about solar energy and planning within the whole region for urban planning and environment departments, real estate offices, together with politicians, investors, and large property and utilities owners. These trainings will provide basic knowledge about solar energy technologies to the possibilities of using local plans and strategic tools to improve the number of solar energy installations.

- Role model: New PV and solar thermal installations will be installed on public buildings, so that the City of Malmö will continue as a role model for other stakeholders in the use of solar energy.

\section{Vitoria-Gasteiz}

\subsection{Background}

In the year 2008 the City of Vitoria-Gasteiz has 100,272 buildings. Several homogeneous areas can be found. Refurbishment activities are increasing moderately in Vitoria-Gasteiz. There are some districts built in the sixties and seventies that need to be refurbished or demolished. Some of these refurbishments have been made to lower the energy demand of the old buildings. The energy supply infrastructure consists of generation and cogeneration plants powered by gas, of private ownership, cogeneration plants powered by biogas, owned by the municipality and distribution infrastructures of electricity and gas. The current installed solar (thermal/photovoltaic) capacity in Vitoria-Gasteiz is 2.68 MWp solar PV and 11.75 MW (16,685 sqm) of solar thermal, contributing in a $0.1 \%$ to the local energy mix. The main criterion for the integration of solar energy in urban planning is the national Technical Building Code, with 2 parts specifically related with active solar technologies, minimum solar contribution to Sanitary Hot Water and minimum photovoltaic contribution to electricity. At local level, there are two instruments that ask for further requirements on solar energy, minimum passive solar requirements for new buildings and that the façade of certain social buildings can be leasehold by the municipality.

\subsection{Action plans}

In Spain the National Action Plan for Renewable Energies 2011-2020 that will comply with the EU Directive 2009/28/CE is under development. However, present estimations of the Spanish Government about RES contribution to final net energy consumption will amount to $22.7 \%$ in 2020 (exceeding the national target established at $20 \%$ ) and $42.7 \%$ for RES contribution to electricity 
generation in the same year. The objectives of the existing National Plan for Renewable Energies 2005-2010 have already been met in relation to PV technology but for solar thermal systems estimations indicate that $49 \%$ of the target will be achieved by the end of 2010 .

In 2007 the City of Vitoria-Gasteiz approved the Local Energy Plan 20072012 , setting targets for energy consumption reduction of $9 \%$ (compared to 2004). In addition, due to the signing of the "Covenant of Mayors" document in 2009, Vitoria-Gasteiz has to adapt its targets to the new commitment of going beyond the $20 \% \mathrm{CO}_{2}$ emission reduction and the promotion of renewable energy. For this reason, Vitoria-Gasteiz is currently working on a new "Fight against Climate Change Plan", a "Climate Change Adaptation Strategy" and an "Energetic Ordinance" where new targets and actions will be set to reduce $\mathrm{CO}_{2}$ emission and promote renewable energies. The existing draft of the "Fight against Climate Change Plan" already establishes the following targets: 70,000 sqm of solar thermal, $10 \mathrm{MWp}$ of solar PV, $9 \%$ on energy savings and $24.5 \%$ of $\mathrm{CO}_{2}$ emission reduction by 2020. A detailed study to quantify the urban solar potential is considered of highest priority within the Action Plan in order to identify the realistic possibilities of solar energy use in Vitoria-Gasteiz. Within the Vitoria-Gasteiz solar Action Plan the following targets have been set :

- Identification of the realistic solar potential at municipal level by 2012. A methodology for the assessment of the realistic solar potential of urban areas will be developed and applied to the district of Lakua (2009-2010). On base of the slightly modifiedthe methodology the realistic solar potential of the industrial area of Jundiz and the complete city of Vitoria-Gasteiz will be assed.

- Integration of solar requirements in the Urban Master Plan and Energetic Ordinance by 2015: A planning guideline for passive and active PV solar energy will be developed and included in the city Urban Master Plan.

- Mobilization of $10 \%$ of the assessed solar potential in the existing industrial area of the city, Jundiz, by 2015.

\section{Conclusion}

The work done on the action plans and pilot actions definition served mainly to enhance a discussion and an exchange between the different stakeholders of each city. Although the framework and legislative context of each city is different, several pilot actions are common in the sense of their objective. Their application will be a good opportunity for testing specific methods and different ways of working together. The pilot actions are presented on the European project website POLIS: www.polis-solar.eu

\section{References}

[1] Estefanía Caamaño-Martin, Ester Higueras, Fco. Javier Neila (Universidad Politécnica de Madrid), Work Package 3: Development of City Action Plans \& Pilot Actions: Madrid 2010. 
698 The Sustainable City VII, Vol. 2

[2] City of Lyon, Solar Action Plan - Grand Lyon: Lyon. 2010.

[3] City of Paris, Solar Action Plan - City of Paris: Paris, 2010.

[4] Landeshauptstadt München, Identifizierung und Mobilisierung solarer Potenziale mittels lokaler Strategien im Städtebau und strategischer Planung: München, 2010.

[5] City of Munich, Solar Action Plan - City of Munich: Munich, 2010.

[6] City of Lisbon, Solar Action Plan-City of Lisbon: Lisbon, 2010.

[7] City of Malmö: Solar Action Plan - City of Malmö: Malmö, 2010.

[8] City of Vitoria-Gasteiz, Solar Action Plan - City of Vitoria-Gasteiz: VitoriaGasteiz, 2010. 